\title{
Effect of a constant magnet position and intensity on a copper layer obtained by DC electrodeposition
}

\author{
F.B. Susetyo, ${ }^{1,2}$ B. Soegijono ${ }^{1}{ }^{1} *$ and Yusmaniar $^{3}(\mathbb{C}$ \\ ${ }^{1}$ Department of Physic Universitas Indonesia, Depok 16424, Indonesia \\ ${ }^{2}$ Department of Mechanical Engineering Universitas Negeri Jakarta, Jakarta 13220, \\ Indonesia \\ ${ }^{3}$ Department of Chemistry Universitas Negeri Jakarta, Jakarta 13220, Indonesia \\ *E-mail: naufal@ui.ac.id
}

\begin{abstract}
Copper $(\mathrm{Cu})$ has high electrical and thermal conductivity compared with aluminium (Al); therefore, $\mathrm{Cu}$ has replaced $\mathrm{Al}$ as a metal for interconnects. In particular, $\mathrm{Al}$ coated with $\mathrm{Cu}$ will provide the benefit of reducing production costs. In this work, the $\mathrm{Cu}$ layer was fabricated using an electrodeposition process under the influence of a constant magnetic field. A single constant magnet field is placed perpendicular with a substrate using various magnetic intensities and positioning of the magnetic pole. The cathodic current efficiency, deposition rate, surface morphology, oxygen content, crystallographic orientation, corrosion rate, corrosion potential, and microhardness were measured and analyzed. The results show that by exerting a constant magnet during electrodeposition, the cathodic current efficiency, deposition rate, peak (111) intensities, and hardness of the $\mathrm{Cu}$ layer significant increase. The crystal systems of all the $\mathrm{Cu}$ layer is a cubic structure (FCC) with FM-3M space group, and three significant peaks are seen based on high score refinement. Three significant peaks are seen in (111), (002), and (022) planes with various preferred orientations. The preferred orientation shifted from (022) to (111) plane when a constant magnet was applied. Furthermore, the $\mathrm{Cu} 1-14 \mathrm{~N}$ sample displays better hardness and corrosion resistance with values of $255.2 \mathrm{HV}$ and $0.023 \mathrm{mmpy}$, respectively.
\end{abstract}

Keywords: magnet, position, electrodeposition, copper, Al alloy.

Received: March 17, 2021. Published: June 8, 2021

doi: $\underline{10.17675 / 2305-6894-2021-10-2-18}$

\section{Introduction}

Copper $(\mathrm{Cu})$ is always needed in the electronic industry due to its high electrical conductivity, thermal conductivity, and strength [1-3]. The electrical and thermal conductivity of $\mathrm{Cu}$ is higher than that of aluminum (Al). $\mathrm{Cu}$ has higher electrical stability and lower resistivity $(1.7 \mathrm{~m} \Omega \cdot \mathrm{cm})$ against electromigration than $\mathrm{Al}(3.1 \mathrm{~m} \Omega \cdot \mathrm{cm})[4,5]$. Therefore, $\mathrm{Cu}$ has replaced $\mathrm{Al}$ as a metal for interconnect metallization in the semiconductor industry. In recent years the price of $\mathrm{Cu}$ has been higher than that of $\mathrm{Al}$. For that reason, $\mathrm{Al}$ coated with $\mathrm{Cu}$ will provide the benefit by a significant reduction of production costs. To fabricate a $\mathrm{Cu}$ layer on $\mathrm{Al}$, scientific and technological aspect need to be tackled in order to 
attain the desired properties. Conventional manufacturing processing is usually controlled by recrystallization methods.

Many methods are used to coat $\mathrm{Al}$ with $\mathrm{Cu}$, such as physical vapor deposition (PVD), chemical vapor deposition (CVD), electroless deposition, and electrodeposition. Through PVD methods, Kadhim et al. fabricated a Cu layer on an Al alloy (AA4015) to improve thermal solar collectors' performance [6]. Kröger et al. coated a $\mathrm{Cu}$ layer for advanced metallization of microelectronic devices by CVD [7]. Yanagimoto et al. have been doing electroless $\mathrm{Cu}$ deposition on $\mathrm{Al}$ nitride substrate with patterned $\mathrm{Cu}$ seed layer in a fully additive-based manner [8]. Electrodeposition is the easiest material deposition method in terms of surface morphology and crystallographic orientation [9].

Moreover, to fabricate a layer of materials, a new method is required for many metals, including $\mathrm{Cu}$. The electrodeposition process in a magnetic field provides many promising properties [10]. The interaction of electric current and magnetic field can lead to a change in grain size [11], smoother deposits [12], and increase the deposition rates [13]. A recent study applies a magnetic field parallel or perpendicular to the electrode surface. However, no significant effect on the electrochemical system was found when a magnetic field was applied perpendicular to an electrode surface. Constant magnetic field applied perpendicular to the electrode surface produces the maximal Lorentz force and causes higher deposition rates [14].

Based on previous work, a lower current density $\left(1 \mathrm{~mA} \cdot \mathrm{cm}^{-2}\right)$ increases the preferred crystallographic orientation at (022) plane [15]. A lower current density also results in a morphology with minor void defects compared to a higher current density [16]. Moreover, adding constant magnets for $800 \mathrm{G}$ and $1400 \mathrm{G}$ lead to shifting the preferred crystallographic orientation from (111) to (022) when the applied current density is $10 \mathrm{~mA} \cdot \mathrm{cm}^{-2}$ and opposite phenomena when applied current density is changed to $30 \mathrm{~mA} \cdot \mathrm{cm}^{-2}$ [17]. The preferred crystallographic orientation has benefits such as the (111) plane features with better corrosion resistance and improves the mechanical properties [18] and the (002) plane is related to grain size [19]. Moreover, the hardness of $\mathrm{Cu}$ films is affected by current density, grain size, and additive amount [20].

The properties of electrodeposited $\mathrm{Cu}$ fabricated at low current density with various constant magnets need further investigation. In this work, we fabricated a $\mathrm{Cu}$ layer onto an Al substrate using an electrodeposition process under a constant magnetic field. The cathodic current efficiency, deposition rate, surface morphology, oxygen content, crystallographic orientation, corrosion rate, corrosion potential, and microhardness will be discussed and analyzed.

\section{Experimental Methods}

A DC power supply was used for the electrodeposition process. The electrodeposition process was performed in an electrolyte containing $0.5 \mathrm{M} \mathrm{CuSO}_{4}$ and $40 \mathrm{~mL} \cdot \mathrm{L}^{-1} \mathrm{H}_{2} \mathrm{SO}_{4}$. A constant magnetic field (north pole and south pole) of 800 and $1400 \mathrm{G}$ was placed 
perpendicular to the surface of the cathode, and it was used for an experiment during the electrodeposition process (Figure $1(\mathrm{a}$ and $\mathrm{b})$ ). The designations of the samples are shown in Table 1.

Table 1. Designations of experiment samples.

\begin{tabular}{cc}
\hline Sample & Remark \\
\hline $\mathrm{Cu} 1$ & Absence of constant magnet \\
$\mathrm{Cu} 1-8 \mathrm{~N}$ & $800 \mathrm{G}$ constant magnet and the north pole near the cathode \\
$\mathrm{Cu} 1-14 \mathrm{~N}$ & $1400 \mathrm{G}$ constant magnet and the north pole near the cathode \\
$\mathrm{Cu} 1-8 \mathrm{~S}$ & $800 \mathrm{G}$ constant magnet and the south pole near the cathode \\
$\mathrm{Cu} 1-14 \mathrm{~S}$ & $1400 \mathrm{G}$ constant magnet and the south pole near the cathode \\
\hline
\end{tabular}

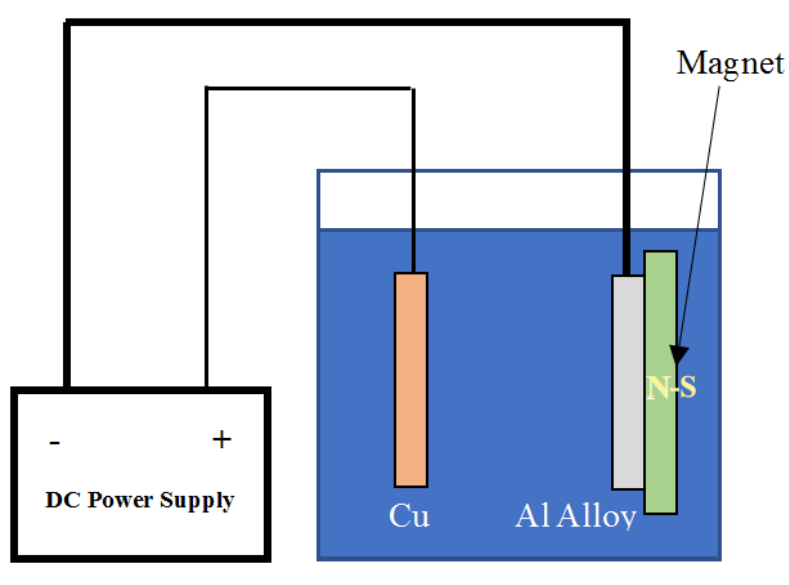

a

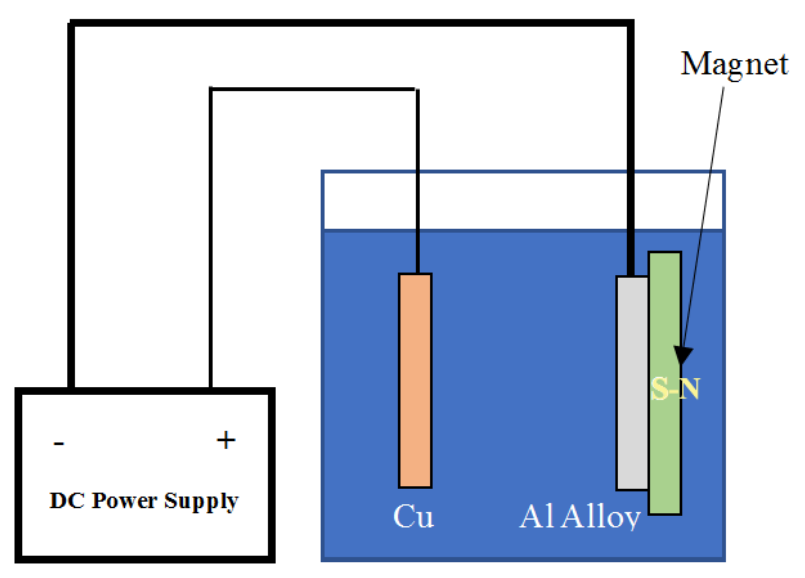

b

Figure 1. Schematic representation of the experimental set-up for $\mathrm{Cu}$ electrodeposition under a magnetic field.

The current density, bath temperature, and deposition time were fixed at $1 \mathrm{~mA} \cdot \mathrm{cm}^{-2}$, $30^{\circ} \mathrm{C}$, and $48 \mathrm{~h}$, respectively. A pure $\mathrm{Cu}$ plate was used as the anode, and $\mathrm{Al}$ alloy with the composition $1.49 \mathrm{wt} \% \mathrm{Mg}, 1.63 \mathrm{wt} \% \mathrm{Fe}$, and $\mathrm{Al}$ balance as the cathode. The microstructure of the cathode is demonstrated in Figure 2. The cathode was polished before electrodeposition, and the surface was checked for conductance before the cathode was plated with copper. If the surface was conductive, the electrodeposition process was carried out. A Cu layer with a thickness of approximately $60 \mu \mathrm{m}$ was electrodeposited on $\mathrm{Al}$ alloy surface.

The surface morphology was observed using a scanning electron microscope (SEM FEI Quanta 650, equipped with EDS Oxford Instrument). 


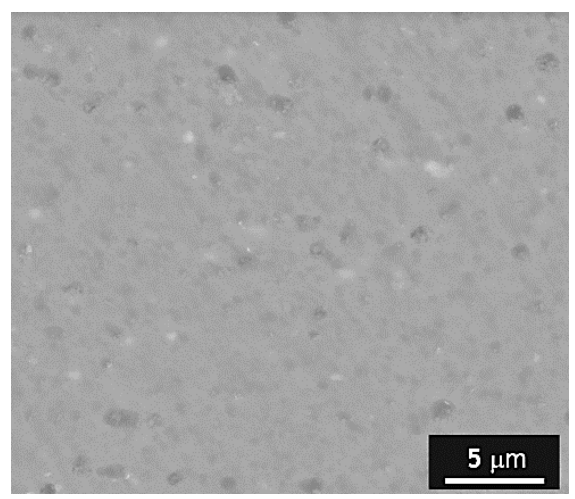

Figure 2. Microstructure of the Al alloy cathode.

The cathodic current efficiency was calculated according to Faraday's law as shown below:

$$
m=\frac{Q M}{n F}=\frac{i t M}{n F}
$$

where $m$ is the mass of the Cu layer, $Q$ is electric charge, $i$ is current, $t$ is time, $F$ is the Faraday constant, $M$ is the atomic mass of the $\mathrm{Cu}$, and $n$ is a number of electrons involved.

The deposition rate was calculated according to the equation below [21]:

$$
v=\frac{1000 \Delta m}{\rho \cdot S \cdot t}
$$

where $v$ is the deposition rate $\left(\mu \mathrm{m} \cdot \mathrm{h}^{-1}\right), \Delta m$ is the mass increment of the sample after deposition $(\mathrm{g}), t$ is the deposition time (h), $S$ is the area of substrates $\left(\mathrm{cm}^{2}\right)$, and $\rho$ is the density $\left(\mathrm{g} \cdot \mathrm{cm}^{-3}\right)$.

Malvern Panalitical Ltd, U.K. (with $\mathrm{Cu} \mathrm{K} \alpha$ ) of XRD, was used to analyze the sample's crystallographic orientation. The XRD measurement was performed from $40^{\circ}$ to $80^{\circ}$ with a $2 \theta$ step size of $0.01^{\circ}$.

A Digi-Ivy DY2311 potentiostat was used to investigate the corrosion behavior using $\mathrm{Ag} / \mathrm{AgCl}$, platinum, and $\mathrm{Al}$ as a reference electrode (RE), counter electrode $(\mathrm{CE})$, and working electrode (WE), respectively. The corrosion behavior was analyzed by potentiodynamic polarization measurements in $3.5 \% \mathrm{NaCl}$ solution at a scan rate of $10 \mathrm{mV} / \mathrm{s}$ at room temperature.

The corrosion resistance $\left(C_{\mathrm{R}}\right)$, corrosion potential $\left(E_{\text {corr }}\right)$, and corrosion current density $\left(I_{\text {corr }}\right)$ were determined by Tafel extrapolation. The corrosion resistance was determined by the equation below.

$$
C_{\mathrm{R}}(m m p y)=C \cdot \frac{M \cdot I_{\text {corr }}}{n \cdot \rho}
$$


Where $C_{\mathrm{R}}$ is the corrosion rate (mmpy), $C$ is a constant (3.27 mmpy), $\mathrm{M}$ is the atomic weight $\left(\mathrm{g} \cdot \mathrm{moL}^{-1}\right), I_{\text {corr }}$ is corrosion current density $\left(\mathrm{A} \cdot \mathrm{cm}^{-2}\right), n$ is the number of electrons involved, and $\rho$ is the density of $\mathrm{Cu}\left(8.96 \mathrm{~g} \cdot \mathrm{cm}^{-3}\right)$.

The Vickers microhardness test was performed at room temperature with MicroMet ${ }^{\circledR}$ 5100 series. The ASTM E384 method was used as the standard microhardness test. The microhardness test load was performed at $100 \mathrm{~g}$ for $10 \mathrm{~s}$, with coverage factor $K=2$ and confidence level $95 \%$.

\section{Results and Discussion}

\subsection{Cathodic current efficiency and deposition rate}

The cathodic current efficiency was calculated from the mass ratio of $\mathrm{Cu}$ plated on $\mathrm{Al}$ and the mass of $\mathrm{Cu}$ calculated by Faraday law by knowing the current and time during electrodeposition. The magnetic field effect on the cathodic current efficiency of various $\mathrm{Cu}$ layers is demonstrated in Figure 3.

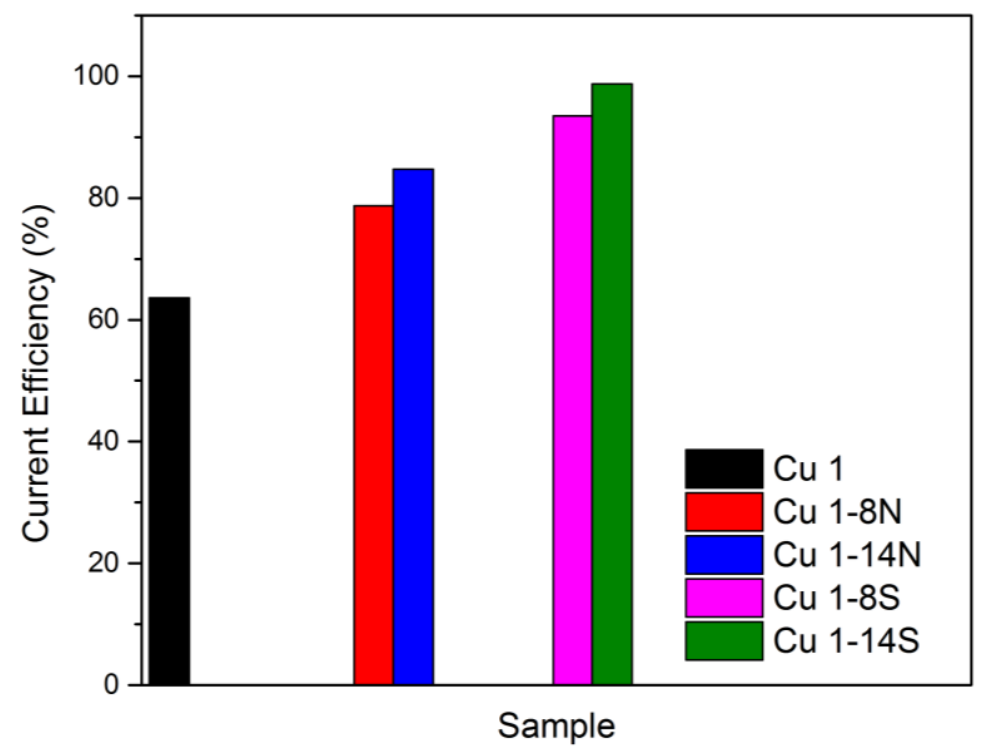

Figure 3. Effect of magnetic field on cathodic current efficiency of $\mathrm{Cu}$ layers.

Based on Figure 3, we can see that a higher magnetic field leads to an increase in cathodic current efficiency. A low value of current efficiency is shown by the sample obtained without applying a magnetic field. This result is similar to other studies where electrodeposition at low current density $\left(0.5 \mathrm{~A} \cdot \mathrm{dm}^{-2}\right)$ resulted in a current efficiency of about $50 \%$ [22]. Another team performed electrodeposition at $0.2 \mathrm{~A} \cdot \mathrm{dm}^{-2}$, and the use of various bath formulas resulted in 75-95\% current efficiency [23]. This result means that many aspects result in differences in current efficiency.

Moreover, a change in the direction of the constant magnet from the north pole to a south pole near and perpendicular to the substrate leads to an increase in the cathodic current 
efficiency. It should be noted that the cathodic current efficiency with constant magnet increased rapidly.

Increasing the magnetic field will increase the convection flow rate, control with the Lorentz force, which induces $\mathrm{Cu}^{2+}$ ions to move faster, and therefore, the current efficiency of the cathodic process increases [24]. The increase in convection flow in an electrolyte solution is called the magnetohydrodynamic (MHD) effect [25]. Besides Lorentz force $\left(F_{\mathrm{L}}\right)$, the presence of a magnetic field will also induce a paramagnetic force $\left(F_{\mathrm{p}}\right)$ that affects the movement of $\mathrm{Cu}^{2+}$ ions [26]. Moreover, hydrogen gas evolution also affects the cathodic current efficiency. A decrease in hydrogen evolution could increase the cathodic current efficiency [23].

The deposition rate behavior of the samples is seen in Figure 4.

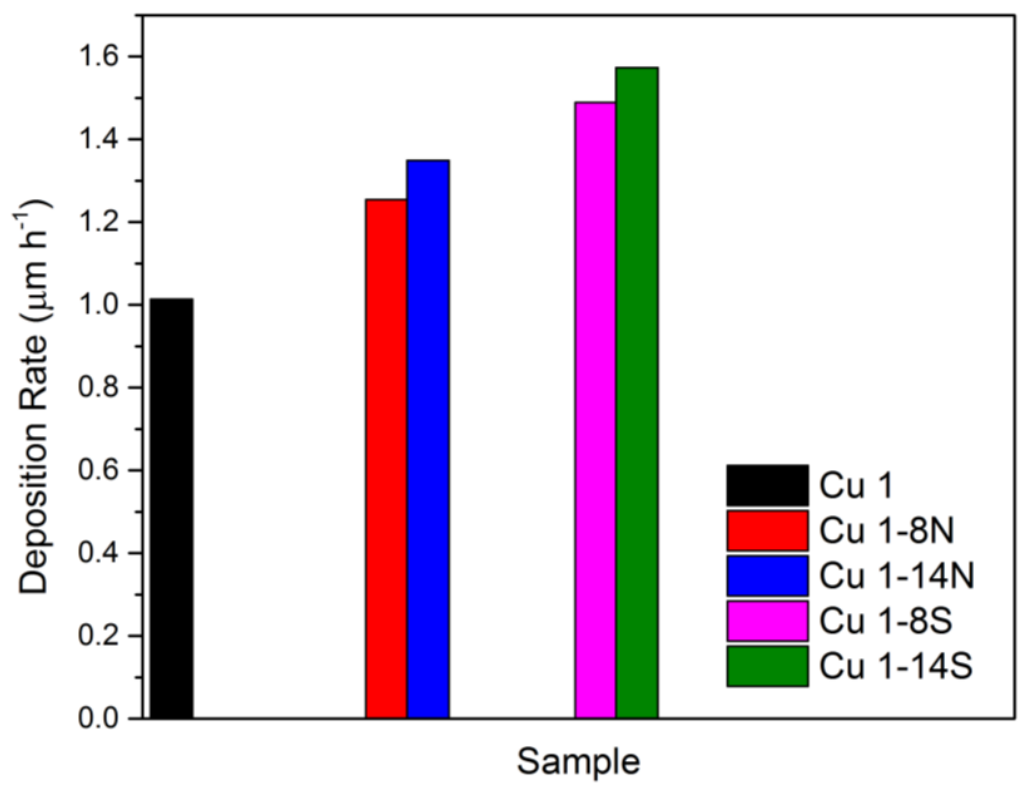

Figure 4. Effect of magnetic field on the deposition rate of $\mathrm{Cu}$.

Based on Figure 4, we can see that the deposition rate was higher in the presence of a constant magnet than in its absence. Furthermore, a change in the direction of the constant magnet from the north pole to the south pole perpendicular to the substrate leads to an increase in the deposition rate. Applying magnetic field during the electrodeposition process leads to a change in the deposition rate induced by Lorentz force $\left(F_{\mathrm{L}}\right)$ [10]. Moreover, the change in deposition rate is also caused by the paramagnetic force gradient $\left(F_{\mathrm{P}}\right)$. The paramagnetic force gradient $\left(F_{\mathrm{P}}\right)$ causes the ion to move in the opposite direction to the applied magnetic field [27]. A paramagnetic gradient force drove $\mathrm{Cu}^{2+}$ ions towards the electrode's edges during the electrodeposition process. Furthermore, similarly to cathodic current efficiency, a decrease in the hydrogen evolution could affect the increased deposition rate [23]. 


\subsection{Scanning Electron Microscope - Energy Dispersive Spectroscopy (SEM-EDS)}

The results of the SEM investigation are shown in Figure 5. The magnetic field's effect with the north pole near the cathode results in higher grain than on the sample with the south pole near the cathode. Different deposition rates affect grain size in each sample (see Figure 5) [28].

The compact and high grain is seen in Figures 5 (b) and (c) where the morphology is similar to the electrodeposition of $\mathrm{Cu}$ with $1 \mathrm{~mA} \cdot \mathrm{cm}^{-2}$ [15]. The smaller grain size is seen in Figures 5 (d) and (e). Moreover, medium grain size is seen in Figure 5 (a). Generally, all samples are close to a faceted structure [17]. Our SEM observation results are different from the work by Aurun et al. who show a nodule form and smoother surface because the method of $\mathrm{Cu}$ deposition was different. Our $\mathrm{Cu}$ deposition is without zincate treatment, whereas Aurun et al. used zincate treatment [18].

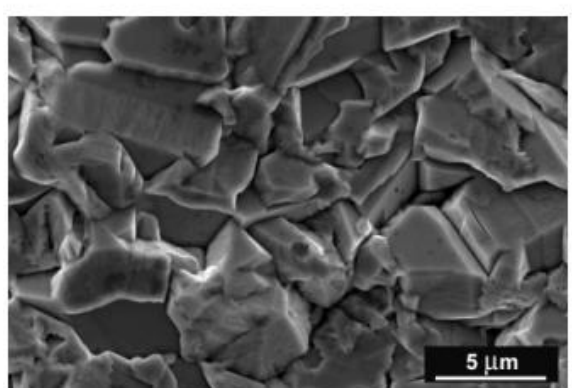

a

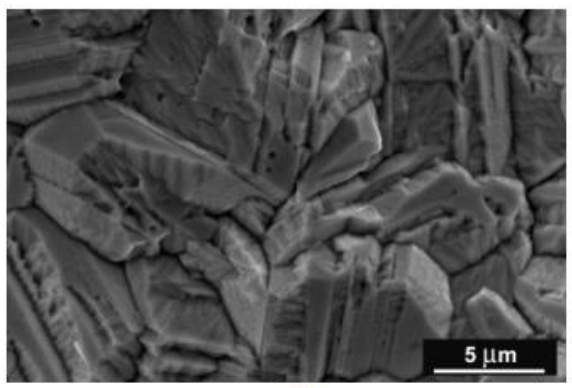

b

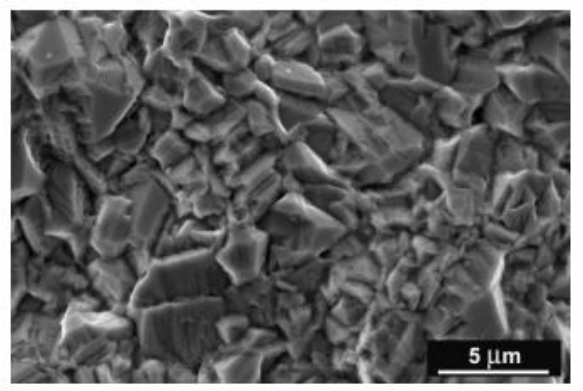

d

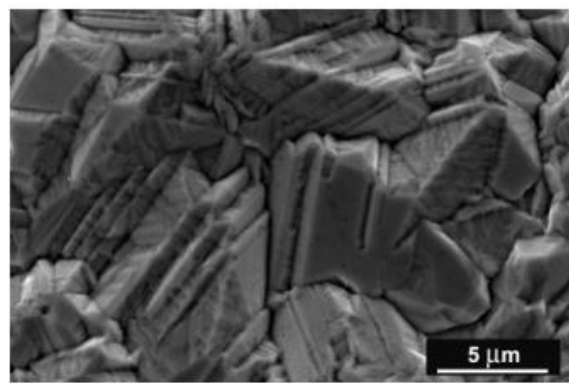

C

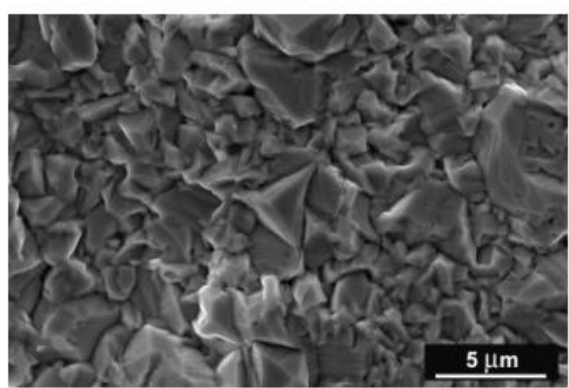

e

Figure 5. $\mathrm{Cu}$ layer fabricated by electrodeposition: (a) $\mathrm{Cu} 1$; (b) $\mathrm{Cu} 1-8 \mathrm{~N}$; (c) $\mathrm{Cu} 1-14 \mathrm{~N}$; (d) $\mathrm{Cu} 1-8 \mathrm{~S}$; (e) $\mathrm{Cu} 1-14 \mathrm{~S}$.

The EDS spectra of the samples are shown in Figures 6-10. EDS spots were used for this investigation. There are three different peaks in the spectra that were analyzed for the $\mathrm{Cu}$ and $\mathrm{O}_{2}$ elements. 


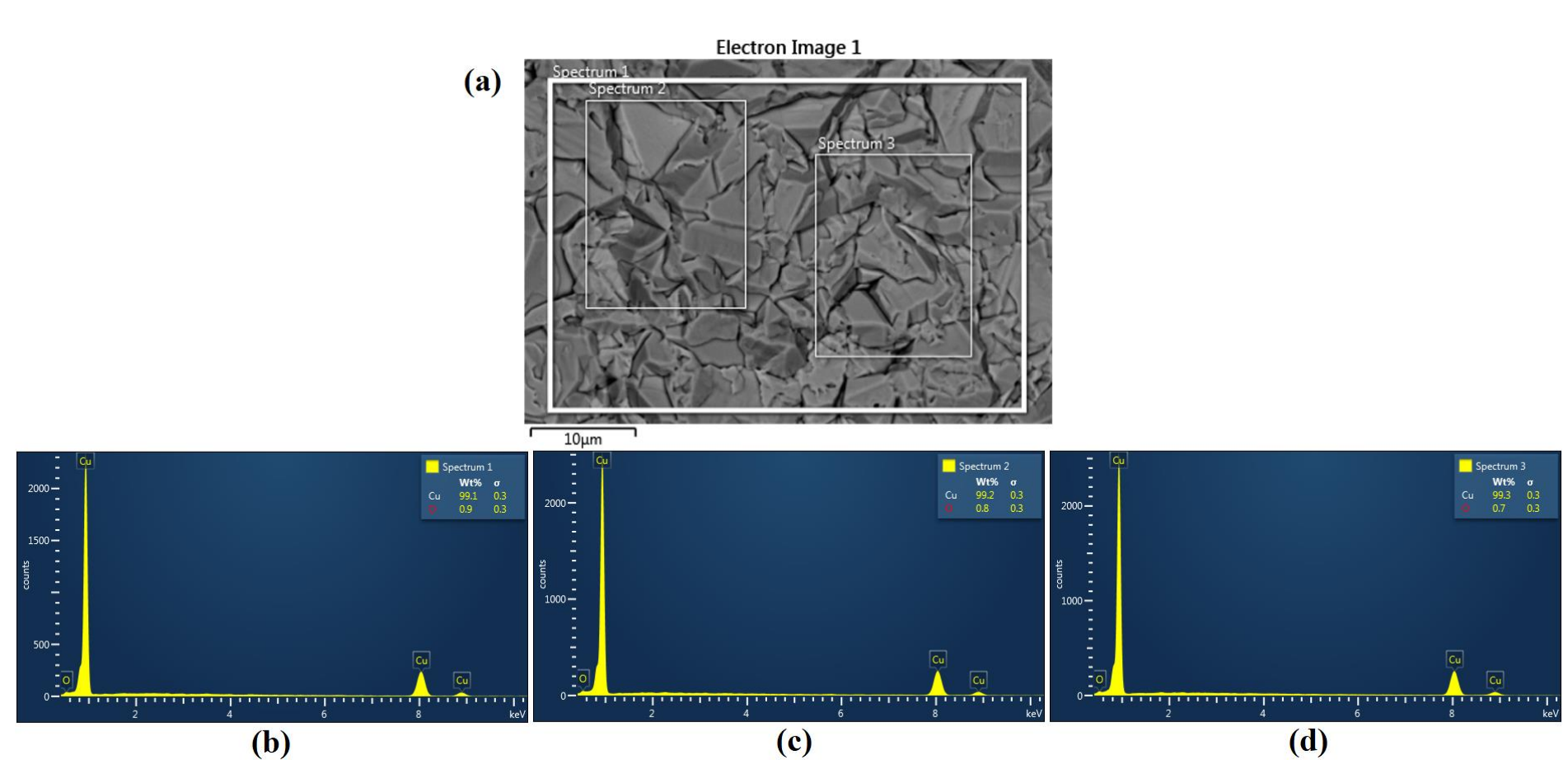

Figure 6. Cu 1 layer: (a) Spot of EDS investigation; (b) Spectrum 1; (c) Spectrum 2; (d) Spectrum 3.

(a)

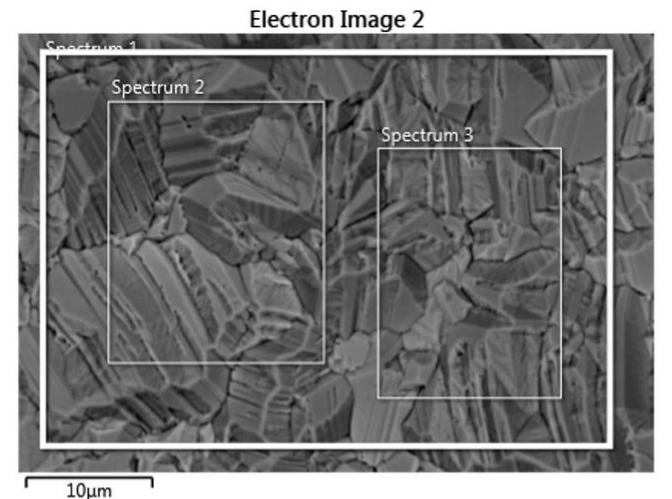

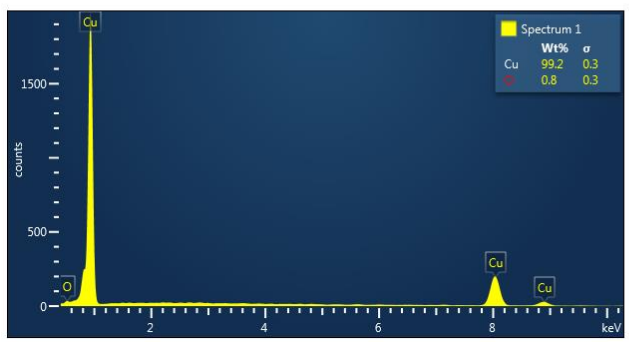

(b)

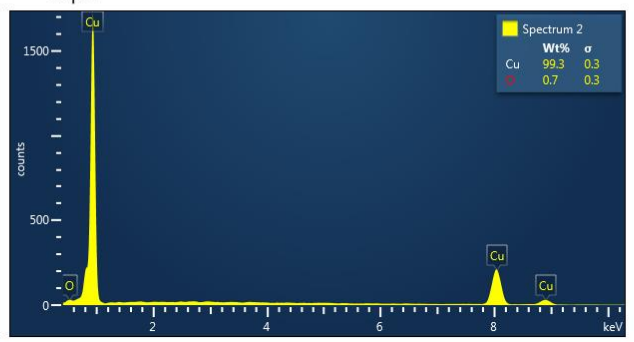

(c)

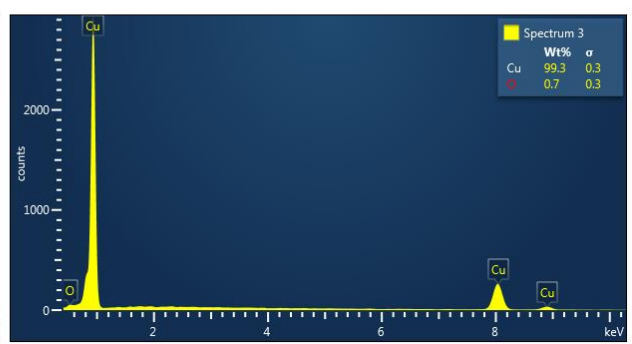

(d)

Figure 7. Cu 1-8N layer: (a) Spot of EDS investigation; (b) Spectrum 1; (c) Spectrum 2; (d) Spectrum 3. 


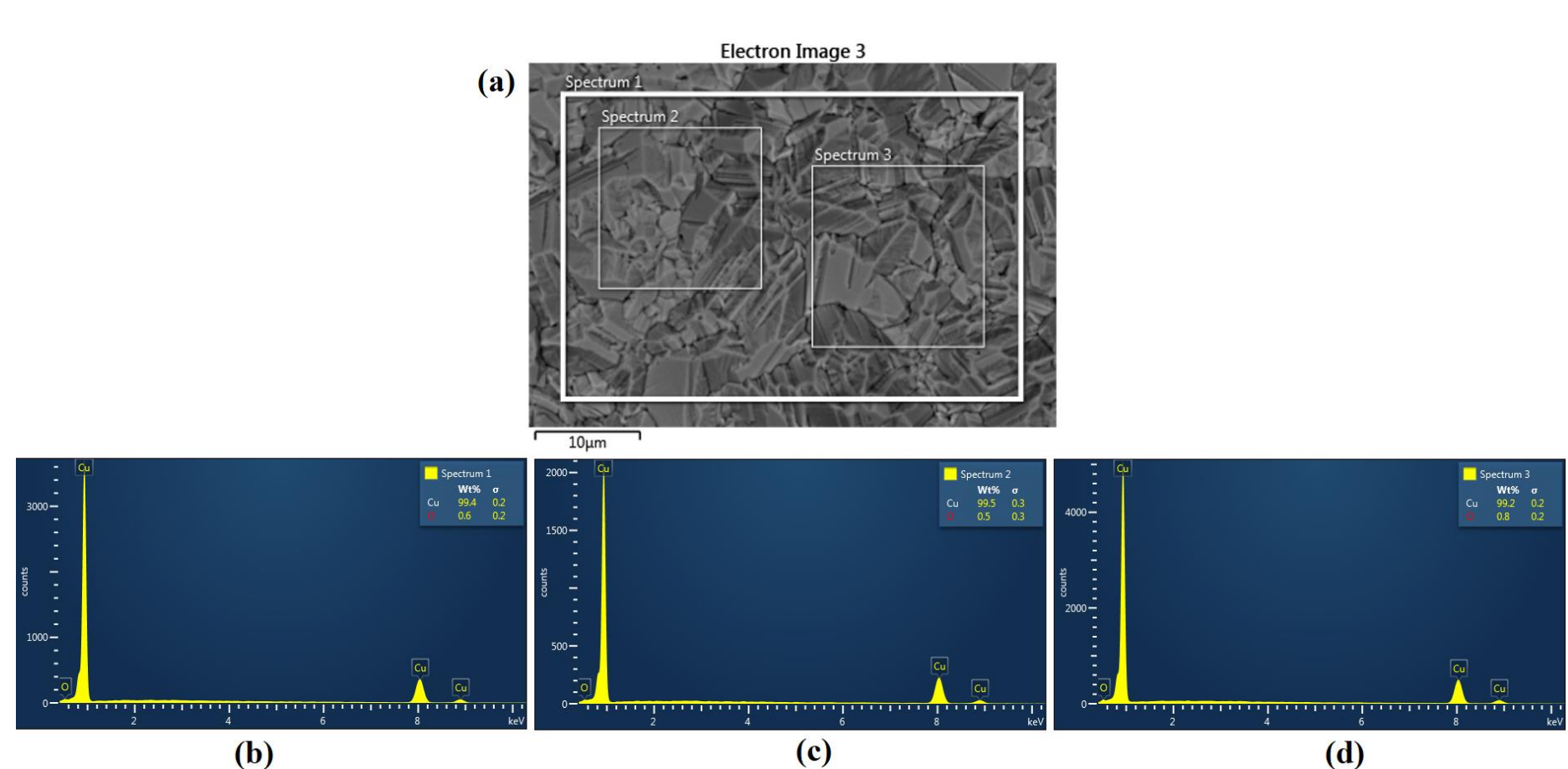

Figure 8. Cu 1-14N layer: (a) Spot of EDS investigation; (b) Spectrum 1; (c) Spectrum 2; (d) Spectrum 3.

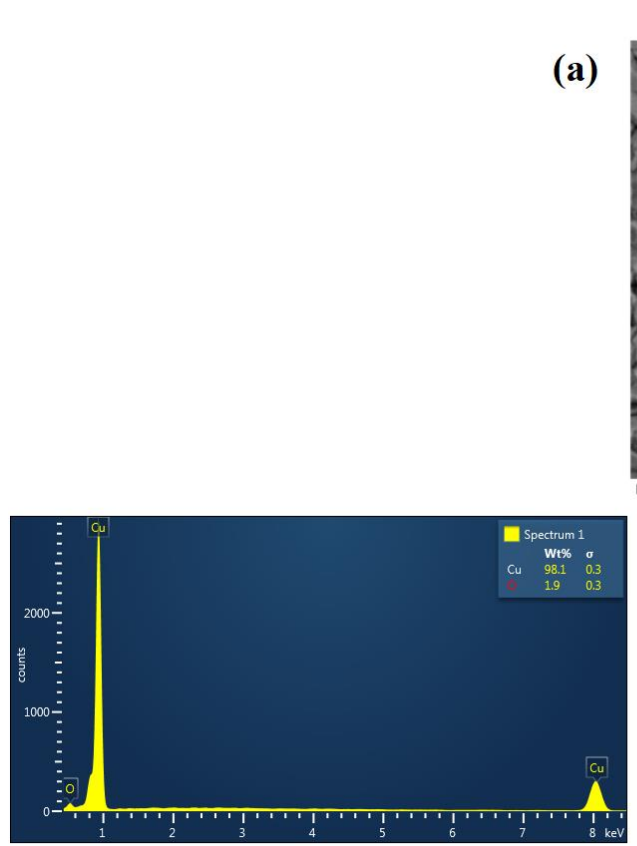

(b)

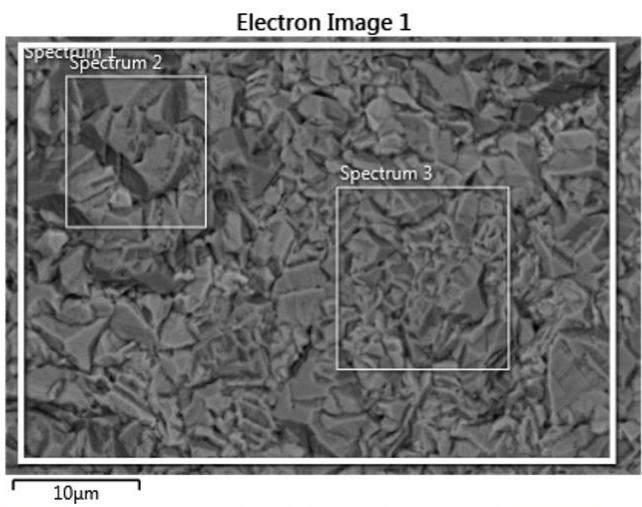

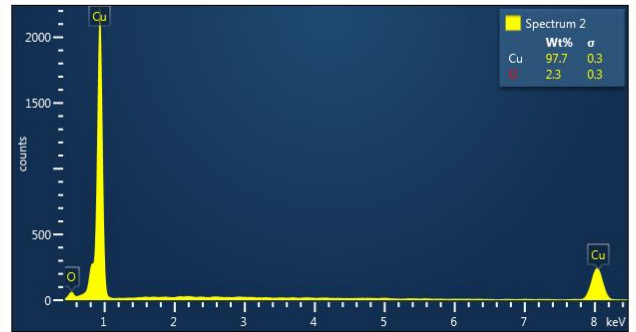

(c)

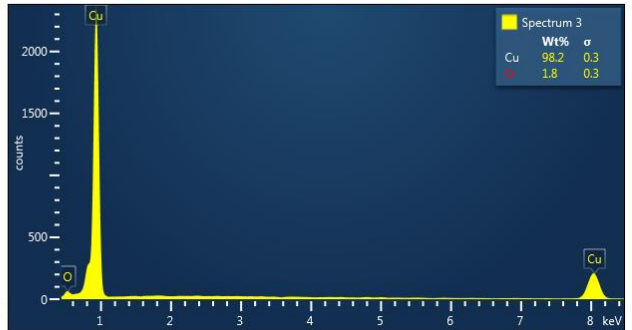

(d)

Figure 9. Cu 1-8S layer: (a) Spot of EDS investigation; (b) Spectrum 1; (c) Spectrum 2; (d) Spectrum 3. 


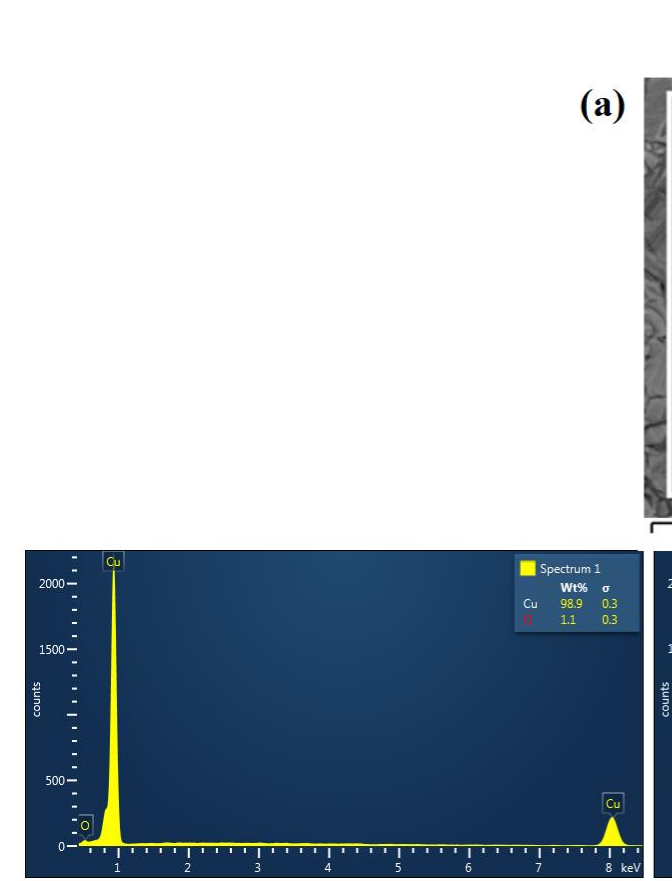

(b)
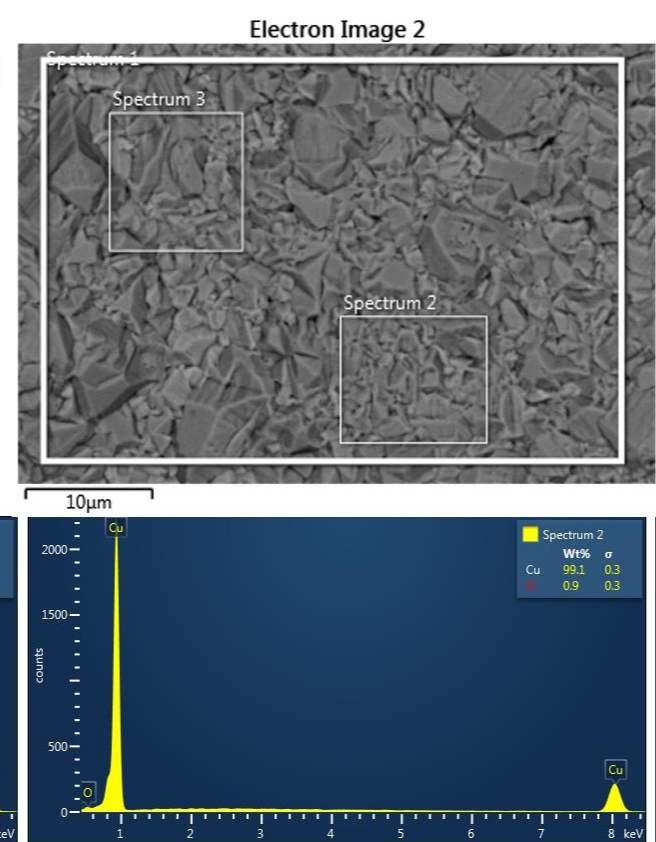

(c)

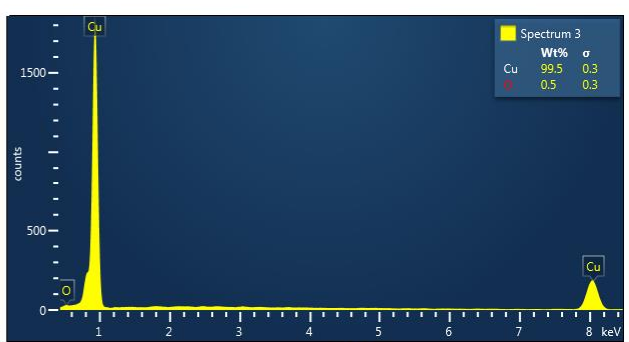

(d)

Figure 10. $\mathrm{Cu}$ 1-14S layer: (a) Spot of EDS investigation; (b) Spectrum 1; (c) Spectrum 2; (d) Spectrum 3.

The percentages of $\mathrm{Cu}$ and $\mathrm{O}_{2}$ based on EDS observation of various samples are listed in Table 2. The absence of a constant magnet during the electrodeposition process gave an $\mathrm{O}_{2}$ amount of $0.8 \mathrm{wt} \%$. The $\mathrm{O}_{2}$ amount of about $0.83 \mathrm{wt} \%$ was found on the $\mathrm{Cu}$ surface and was considered as a residual element [29]. Applying a constant magnet during electrodeposition resulted in variation of the $\mathrm{O}_{2}$ content. It is caused by a constant magnet applied during electrodeposition that would induce turbulence of $\mathrm{Cu}^{2+}$ ions and variation in $\mathrm{Cu}$ and $\mathrm{O}_{2}$ content. Furthermore, the constant magnet attracted $\mathrm{O}_{2}$, while the $\mathrm{O}_{2}$ molecule is a paramagnetic material [17].

Table 2. Distribution of the elements on various samples.

\begin{tabular}{ccccccccccc}
\hline & \multicolumn{2}{c}{$\mathbf{C u} \mathbf{1}$} & \multicolumn{2}{c}{$\mathbf{C u} 1-8 \mathbf{8 N}$} & \multicolumn{2}{c}{$\mathbf{C u} 1-\mathbf{1 4 N}$} & \multicolumn{2}{c}{$\mathbf{C u} 1-8 S$} & \multicolumn{2}{c}{ Cu 1-14S } \\
\cline { 2 - 10 } Spectrum & $\begin{array}{c}\mathrm{Cu} \\
(\mathrm{Wt} \%)\end{array}$ & $\begin{array}{c}\mathrm{O}_{2} \\
(\mathrm{Wt} \%)\end{array}$ & $\begin{array}{c}\mathrm{Cu} \\
(\mathrm{Wt} \%)\end{array}$ & $\begin{array}{c}\mathrm{O}_{2} \\
(\mathrm{Wt} \%)\end{array}$ & $\begin{array}{c}\mathrm{Cu} \\
(\mathrm{Wt} \%)\end{array}$ & $\begin{array}{c}\mathrm{O}_{2} \\
(\mathrm{Wt} \%)\end{array}$ & $\begin{array}{c}\mathrm{Cu} \\
(\mathrm{Wt} \%)\end{array}$ & $\begin{array}{c}\mathrm{O}_{2} \\
(\mathrm{Wt} \%)\end{array}$ & $\begin{array}{c}\mathrm{Cu} \\
(\mathrm{Wt} \%)\end{array}$ & $\begin{array}{c}\mathrm{O}_{2} \\
(\mathrm{Wt} \%)\end{array}$ \\
\hline 1 & 99.1 & 0.9 & 99.2 & 0.8 & 99.4 & 0.6 & 98.1 & 1.9 & 98.9 & 1.1 \\
2 & 99.2 & 0.8 & 99.3 & 0.7 & 99.5 & 0.5 & 97.7 & 2.3 & 99.1 & 0.9 \\
3 & 99.3 & 0.7 & 99.3 & 0.7 & 99.2 & 0.8 & 98.2 & 1.8 & 99.5 & 0.5 \\
\hline Average & 99.2 & 0.8 & 99.3 & 0.7 & 99.4 & 0.6 & 98.0 & 2.0 & 99.2 & 0.8 \\
\hline
\end{tabular}

Based on Table 2, we can see that $\mathrm{Cu} 1-14 \mathrm{~S}$ contains less $\mathrm{O}_{2}$ than the other sample, and the highest amount of $\mathrm{O}_{2}$ is found on $\mathrm{Cu} 1-8 \mathrm{~S}$. A small amount of $\mathrm{O}_{2}$ was also found in 
another research based on an EDS examination [30, 31]. Another reason why $\mathrm{O}_{2}$ is present in the $\mathrm{Cu}$ film based on the EDS results is that $\mathrm{O}_{2}$ was formed when the $\mathrm{Cu}$ layer was in contact with air after the electrodeposition process was complete. The presence of $\mathrm{O}_{2}$ leads to surface roughness [5].

\subsection{X-Ray Diffraction (XRD)}

$\mathrm{XRD}$ spectra of the $\mathrm{Cu}$ layers fabricated with or without the magnetic field are shown in Figure 11.

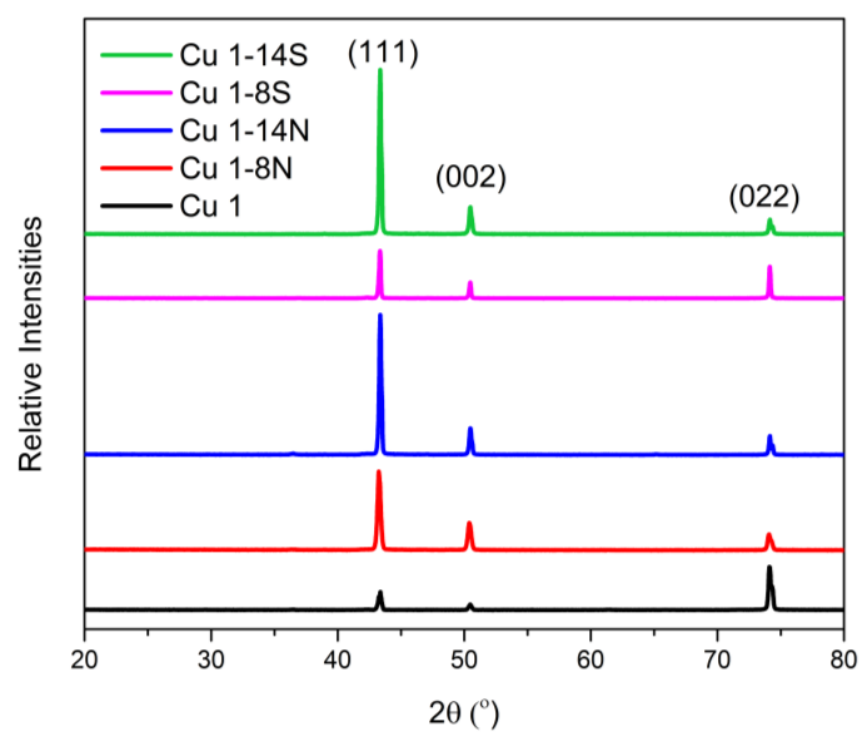

Figure 11. $\mathrm{Cu}$ layers fabricated by electrodeposition with and without magnetic field.

Based on Figure 11, we can see $\mathrm{Cu}$ in cubic structure (FCC) with three peaks between of $2 \theta=20$ and $80^{\circ}$ [32]. The (111), (002), and (022) planes are seen in Figure 11. The (111) plane's intensity was more dominant than the other planes when the constant magnet was applied. These phenomena could be attributed to the smaller surface energy of the (111) plane aligned parallel to the sample's surface. The surface energy of FCC material was $(110)>(001)>(111)$. The (111) plane is parallel to the surface for FCC. The materials offered benefits such as better corrosion resistance.

Furthermore, adding a constant magnet during the electrodeposition process would affect a (022) plane to (111) plane with various intensities. This behavior is similar to previous work [17]. Adding a magnet leads to shifting the preferred plane orientation. The peak heights of each plane are seen in Table 3.

Based on Table 3, we can see that the preferred orientation of sample $\mathrm{Cu} 1$ is on the (022) plane. This result is similar to our previous work, whereby applying $1 \mathrm{~mA} \cdot \mathrm{cm}^{-2}$ current density leads to preferred orientation on the (022) plane [15]. The intensities of preferred orientation in our previous work were higher than in the present one; this is because the electrolyte composition was different from the present work using $\mathrm{CuSO}_{4} \cdot 5 \mathrm{H}_{2} \mathrm{O}$ 
$\left(220 \mathrm{~g} \cdot \mathrm{L}^{-1}\right)$ and $\mathrm{H}_{2} \mathrm{SO}_{4}\left(10 \mathrm{~mL} \cdot \mathrm{L}^{-1}\right)$. The $\mathrm{XRD}$ data were refined with Highscore plus software. The results are presented in Table 4.

Table 3. The peak height for various $h k l \mathrm{Cu}$ layers fabricated by electrodeposition with and without magnetic field.

\begin{tabular}{cclc}
\hline & \multicolumn{3}{c}{$\boldsymbol{h k l}(\mathbf{a . u .})$} \\
\cline { 2 - 4 } Sample & $\mathbf{( 1 1 1 )}$ & $\mathbf{( 0 0 2 )}$ & $\mathbf{( 0 2 2 )}$ \\
\hline $\mathrm{Cu} 1$ & 6264 & 2488 & 13860 \\
$\mathrm{Cu} \mathrm{1-8N}$ & 24699 & 9143 & 5645 \\
$\mathrm{Cu} 1-14 \mathrm{~N}$ & 43225 & 8878 & 6546 \\
$\mathrm{Cu} 1-8 \mathrm{~S}$ & 18351 & 6535 & 10766 \\
$\mathrm{Cu} 1-14 \mathrm{~S}$ & 50582 & 8977 & 5196 \\
\hline
\end{tabular}

Table 4. Crystallographic parameters of $\mathrm{Cu}$ electrodeposition.

\begin{tabular}{cccccc}
\hline \multirow{2}{*}{ Parameters } & \multicolumn{5}{c}{ Samples } \\
\cline { 2 - 6 } & Cu 1 & Cu 1-8N & Cu 1-14N & Cu 1-8S & Cu 1-14S \\
\hline Crystal System & Cubic FCC & Cubic FCC & Cubic FCC & Cubic FCC & Cubic FCC \\
Space Group & FM-3M & FM-3M & FM-3M & FM-3M & FM-3M \\
$a=b=c(\AA)$ & 3.6133 & 3.6132 & 3.6154 & 3.6146 & 3.6149 \\
Density $\left(\mathrm{g} \cdot \mathrm{cm}^{-3}\right)$ & 8.95 & 8.91 & 8.37 & 8.94 & 8.55 \\
Crystallite Size $(\mathrm{nm})$ & 23 & 33 & 57 & 32 & 77 \\
Microstrain $(\%)$ & 0.141 & 0.000 & 0.000 & 0.105 & 0.006 \\
Rwp (\%) & 8.39 & 5.73 & 7.59 & 9.33 & 7.88 \\
GOF & 2.28 & 1.26 & 2.19 & 2.99 & 2.28 \\
\hline
\end{tabular}

Based on Table 4, we can see that various crystallite sizes are produced by different methods.

\subsection{Potentiodynamic Polarization}

The potentiodynamic polarization curves of various $\mathrm{Cu}$ samples are shown in Figure 12.

Based on Figure 12, we can see that the sample's corrosion potential is between -0.5 and $-0.709 \mathrm{~V}$ vs $\mathrm{Ag} / \mathrm{AgCl}$. Rhen et al. found that magnetic field could change the potentiodynamic polarization curve [33]. Yu et al. found that magnetic field affected the corrosion potential [34]. It seems that the potential of the $\mathrm{Cu} 1-14 \mathrm{~N}$ sample shifted to a higher potential than the other samples. 

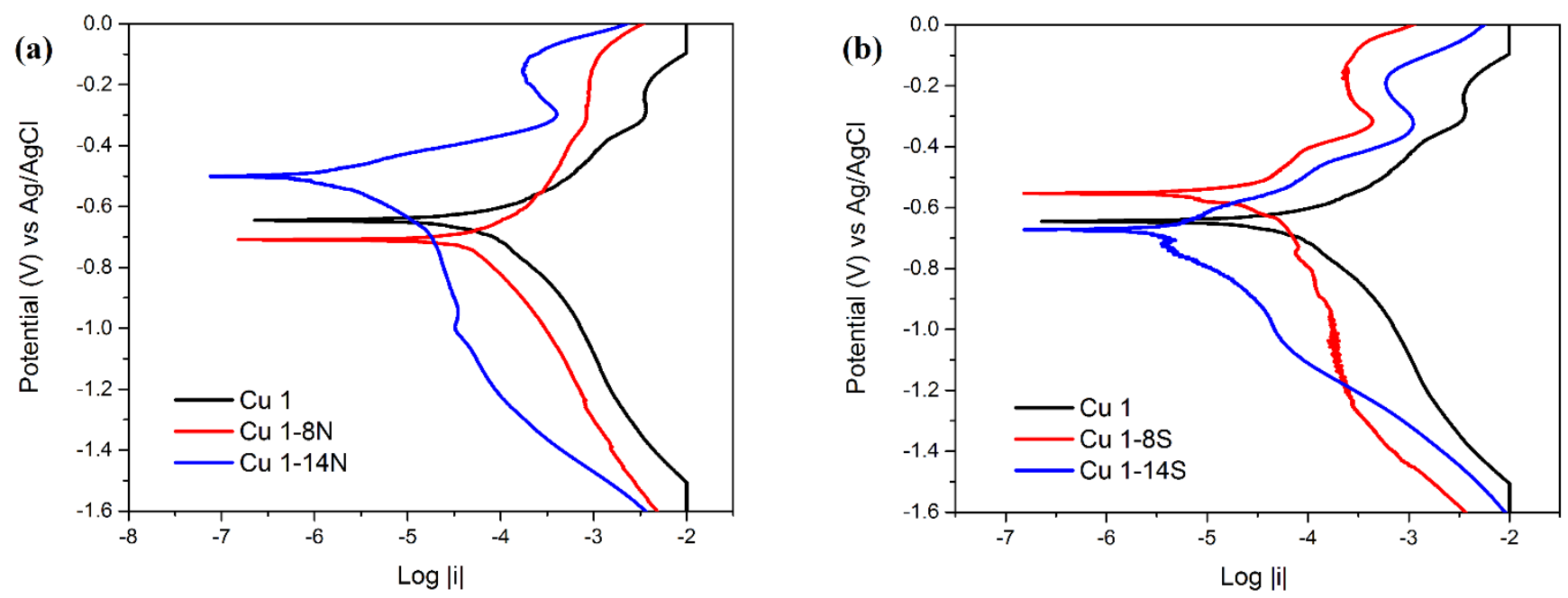

Figure 12. Potentiodynamic polarization curve of $\mathrm{Cu}$ layers fabricated by electrodeposition with and without magnetic field (a) North pole and (b) South pole.

Table 5 shows the results on the corrosion current density $\left(I_{\text {corr }}\right)$, corrosion potential $\left(E_{\text {corr }}, \mathrm{V}\right)$, and corrosion rates $\left(C_{\mathrm{R}}, \mathrm{mmpy}\right)$ based on potentiodynamic polarization measurements.

Table 5. Corrosion current density, corrosion potential, and corrosion rates of $\mathrm{Cu}$ layers fabricated by electrodeposition with and without magnetic field.

\begin{tabular}{cccc}
\hline Sample & $\boldsymbol{I}$ corr, $\left(\mathbf{A} \cdot \mathbf{c m}^{-2}\right)$ & $\boldsymbol{E}_{\text {corr }},(\mathbf{V}) \boldsymbol{v s} \mathbf{A g} / \mathbf{A g C l}$ & $\boldsymbol{C}_{\mathbf{R}}(\mathbf{m m p y})$ \\
\hline $\mathrm{Cu} 1$ & $3.41 \cdot 10^{-5}$ & -0.645 & 0.372 \\
$\mathrm{Cu} 1-8 \mathrm{~N}$ & $4.91 \cdot 10^{-5}$ & -0.709 & 0.535 \\
$\mathrm{Cu} 1-14 \mathrm{~N}$ & $2.12 \cdot 10^{-6}$ & -0.500 & 0.023 \\
$\mathrm{Cu} 1-8 \mathrm{~S}$ & $1.65 \cdot 10^{-5}$ & -0.553 & 0.180 \\
$\mathrm{Cu} 1-14 \mathrm{~S}$ & $7.24 \cdot 10^{-6}$ & -0.673 & 0.079 \\
\hline
\end{tabular}

Based on Table 5 we can see that a lower corrosion rate is seen on the $\mathrm{Cu} 1-14 \mathrm{~N}$. This is probably because the sample's surface morphology is more compact, and the peak intensities of the (111) plane are higher. Compared with bulk $\mathrm{Cu}$, the corrosion current of bulk $\mathrm{Cu}$ in $3.5 \% \mathrm{NaCl}$ about $3.24 \cdot 10^{-5} \mathrm{~A} \cdot \mathrm{cm}^{-2}$ [35].

\subsection{Microhardness}

A measure of resistance to localized plastic deformation induced by an external force is called hardness. The hardness was estimated using a Vickers microhardness tester. The results of microhardness measurements are presented in Figure 13. 


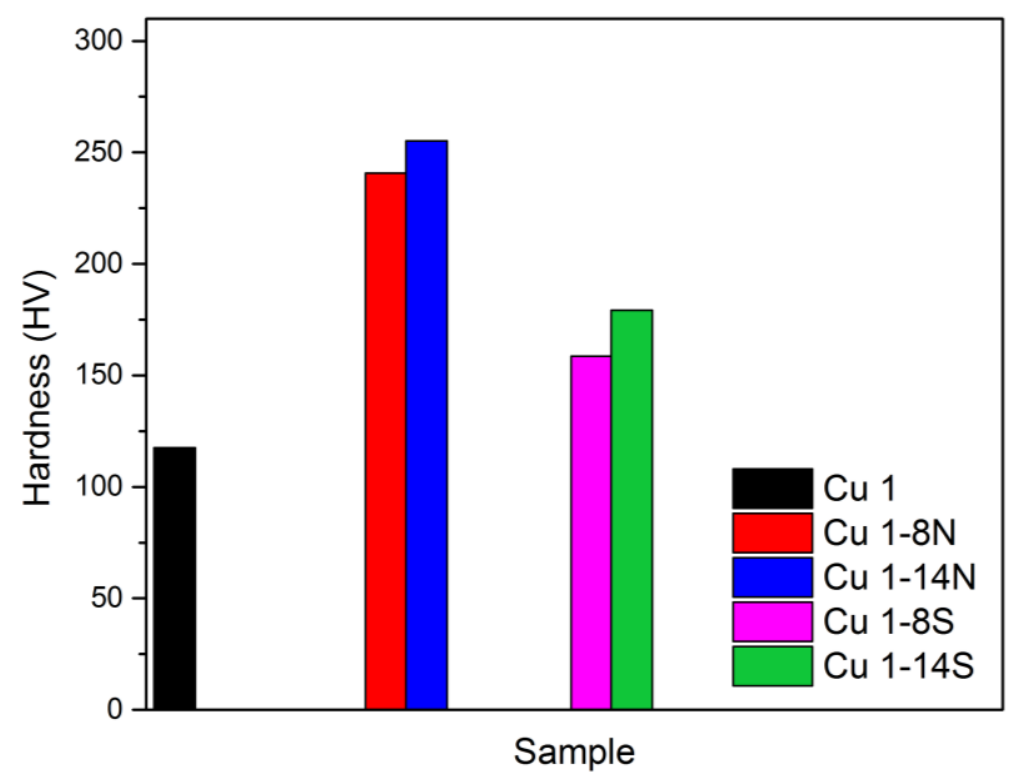

Figure 13. Vickers microhardness of $\mathrm{Cu}$ layers fabricated by electrodeposition with and without magnetic field.

Based on Figure 13, we can see the values of the hardness of $\mathrm{Cu} 1, \mathrm{Cu} 1-8 \mathrm{~N}$, $\mathrm{Cu} 1-14 \mathrm{~N}, \mathrm{Cu} 1-8 \mathrm{~S}$, and $\mathrm{Cu} 1-14 \mathrm{~S}$ are 117.6, 240.8, 255.2, 158.6, and 179.2 HV, respectively. The lowest hardness is seen in the $\mathrm{Cu} 1$ sample, and the better hardness is seen in the $\mathrm{Cu}-14$ sample. To compare, the hardness of a $\mathrm{Cu}$ sheet is from 70 to $100 \mathrm{HV}$ [36], whereas a $\mathrm{Cu}$ layer produced by electrodeposition has a hardness from $22.94 \mathrm{HV}$ to 114.7 HV [37].

The hardness value of the material is closely related to crystallite size. Hakamada et al. found a $\mathrm{Cu}$ layer with a grain size of $31 \mathrm{~nm}$ resulting in hardness $266 \mathrm{HV}$ [20]. Furthermore, Augustin et al. found that the best hardness corresponded to the lowest crystallite size [18]. This result contradicts our result; a larger crystallite size results in a higher hardness. There is probably a relationship between the $\mathrm{O}_{2}$ content formed in the $\mathrm{Cu}$ layer based on the EDS examination. Since $\mathrm{O}_{2}$ in a $\mathrm{Cu}$ layer could be in $\mathrm{CuO}$ form and increase the hardness, these phenomena need further investigation.

\section{Conclusion}

The direction and magnitude of a magnetic field applied on the sample's surface during the electrodeposition process affect the cathodic current efficiency, deposition rate, surface morphology, oxygen content, crystallography, corrosion rate, corrosion potential, and microhardness.

\section{Acknowledgment}

The authors would like to thank the Ministry of higher education for financial support with NKB-3000/UN2.RST/HKP.05.00/2020. 


\section{References}

1. O.Y. Grafov, L.P. Kazansky, S.V. Dubinskaya and Yu.I. Kuznetsov, Adsorption of depocolin and inhibition of copper dissolution in aqueous solutions, Int. J. Corros. Scale Inhib., 2019, 8, no. 3, 549-559. doi: 10.17675/2305-6894-2019-8-3-6

2. N. M'hanni, M. Galai, M. Ouakki, M.E. Touhami, E.H. Rifi and Z. Asfari, Comparative study of the copper inhibition of two $\left[\mathrm{H}_{4} \mathrm{~L}\right]$ calixarenic molecules in sulfuric acid medium, Int. J. Corros. Scale Inhib., 2020, 9, no. 3, 1037-1048. doi: 10.17675/2305-6894-20209-3-16

3. H.I. Al-Itawi, G.M. Al-Mazaideh, A.E. Al-Rawajfeh, A.M. Al-Ma'abreh and A. Marashdeh, The effect of some green inhibitors on the corrosion rate of $\mathrm{Cu}, \mathrm{Fe}$ and Al metals, Int. J. Corros. Scale Inhib., 2019, 8, no. 2, 199-211. doi: 10.17675/23056894-2019-8-2-3

4. J. Neuner, I. Zienert, A. Peeva, A. Preuße, P. Kücher and J.W. Bartha, Microstructure in copper interconnects - Influence of plating additive concentration, Microelectron. Eng., 2010, 87, no. 3, 254-257. doi: 10.1016/j.mee.2009.07.019

5. C.F. Tsang and J. Woo, Effect of nitrogen and oxygen annealing on the morphology and hardness behavior of copper thin films, Mater. Charact., 2000, 45, no. 3, 187-194. doi: 10.1016/S1044-5803(00)00072-3

6. M.J. Kadhim, K.A. Sukkar and A.S. Abbas, Copper Thin Film Deposited by PVD on Aluminum AA4015 substrate for thermal solar application, IOP Conf. Ser.: Mater. Sci. Eng., 2019, 518, no. 3, 1-12. doi: 10.1088/1757-899X/518/3/032048

7. R. Kröger, M. Eizenberg, D. Cong, N. Yoshida, L.Y. Chen, S. Ramaswami and D. Carl, Properties of Copper Films Prepared by Chemical Vapor Deposition for Advanced Metallization of Microelectronic Devices, J. Electrochem. Soc., 1999, 146, no. 9, 32483254. doi: $10.1149 / 1.1392462$

8. H. Yanagimoto, S. Deki, K. Akamatsu and K. Gotoh, Selective electroless copper deposition on aluminum nitride substrate with a patterned copper seed layer, Thin Solid Films, 2005, 491, 18-22. doi: 10.1016/j.tsf.2004.08.177

9. R. Sen, S. Das and K. Das, The effect of bath temperature on the crystallite size and microstructure of $\mathrm{Ni}-\mathrm{CeO}_{2}$ nanocomposite coating, Mater. Charact., 2011, 62, no. 3, 257-262. doi: 10.1016/j.matchar.2011.01.013

10. Y. Zhang, B. Yuan, L. Li and C. Wang, Edge electrodeposition effect of cobalt under an external magnetic field, J. Electroanal. Chem., 2020, 865, 114143. doi: 10.1016/i.jelechem.2020.114143

11. H.A. Murdoch, D. Yin, E. Hernández-Rivera and A.K. Giri, Effect of applied magnetic field on the microstructure of electrodeposited copper, Electrochem. Commun., 2018, 97, 11-15. doi: $10.1016 /$ j.elecom.2018.09.013

12. H. Matsushima, T. Nohira, I. Mogi and Y. Ito, Effects of magnetic fields on iron electrodeposition, Surf. Coat. Technol., 2004, 179, no. 2-3, 245-251. doi: $\underline{10.1016 / \mathrm{S} 0257-8972(03) 00860-0}$ 
13. G. Hinds, F.E. Spada, J.M.D. Coey, T.R. Ní Mhíocháin and M.E.G. Lyons, Magnetic field effects on copper electrolysis, J. Phys. Chem. B, 2001, 105, no. 39, 9487-9502. doi: $10.1021 / \mathrm{jp} 010581 \mathrm{u}$

14. M. Zieliński, Effects of constant magnetic field on the electrodeposition reactions and cobalt-tungsten alloy structure, Mater. Chem. Phys., 2013, 141, no. 1, 370-377. doi: 10.1016/j.matchemphys.2013.05.025

15. B. Soegijono, F.B. Susetyo, E.U.M. Situmorang and Yusmaniar, Effect of Current Density on Crystallographic Orientation, and Oxidation Behavior of Copper Plated on Aluminum Substrate, Asian J. Appl. Sci., 2020, 8, no. 4, 200-207. doi: 10.24203/ajas.v8i4.6287

16. H.P. Feng, M.Y. Cheng, Y.L. Wang, S.C. Chang, Y.Y. Wang and C.C. Wan, Mechanism for $\mathrm{Cu}$ void defect on various electroplated film conditions, Thin Solid Films, 2006, 498, no. 1-2, 56-59. doi: 10.1016/j.tsf.2005.07.062

17. B. Soegijono and F.B. Susetyo, Electrodeposition of Paramagnetic Copper Film under Magnetic Field on Paramagnetic Aluminum Alloy Substrates, e-J. Surf. Sci. Nanotechnol., 2020, 18, 281-288. doi: 10.1380/ejssnt.2020.281

18. A. Augustin, P. Huilgol, K.R. Udupa and U. Bhat K, Effect of current density during electrodeposition on microstructure and hardness of textured $\mathrm{Cu}$ coating in the application of antimicrobial Al touch surface, J. Mech. Behav. Biomed. Mater., 2016, 63, 352-360. doi: 10.1016/j.jmbbm.2016.07.013

19. H. Zhao, L. Liu, J. Zhu, Y. Tang and W. Hu, Microstructure and corrosion behavior of electrodeposited nickel prepared from a sulphamate bath, Mater. Lett., 2007, 61, no. 7, 1605-1608. doi: 10.1016/j.matlet.2006.07.178

20. M. Hakamada, Y. Nakamoto, H. Matsumoto, H. Iwasaki, Y. Chen, H. Kusuda and M. Mabuchi, Relationship between hardness and grain size in electrodeposited copper films, Mater. Sci. Eng. A., 2007, 457, no. 1-2, 120-126. doi: 10.1016/j.msea.2006.12.101

21. J. Lu, M. Wang, X. Deng, J. Yan, J. Yun and S. Jiao, Evaluation of $\mathrm{K}_{3} \mathrm{Fe}(\mathrm{CN})_{6}$ on Deposition Behavior and Structure of Electroless Copper Plating, Electrochemistry, 2019, 87, no. 4, 214-219. doi: 10.5796/electrochemistry.19-00010

22. Z.A. Hamid and A.A. Aal, New environmentally friendly non-cyanide alkaline electrolyte for copper electroplating, Surf. Coat. Technol., 2009, 203, no. 10-11, 13601365. doi: $10.1016 /$ j.surfcoat.2008.11.001

23. R. Sekar, Synergistic effect of additives on electrodeposition of copper from cyanidefree electrolytes and its structural and morphological characteristics, Trans. Nonferrous Met. Soc. China., 2017, 27, no. 7, 1665-1676. doi: 10.1016/S1003-6326(17)60189-4

24. M. Uhlemann, A. Krause and A. Gebert, Effect of a magnetic field on the local pH value in front of the electrode surface during electrodeposition of Co, J. Electroanal. Chem., 2005, 577, no. 1, 19-24. doi: 10.1016/j.jelechem.2004.11.009

25. M.S. Tillack and N.B. Morley, Magnetohydrodynamics. Standard Handbook for Electrical Engineers, McGraw Hill, 1998. 
26. B.N. Park, Y.S. Sohn and S.Y. Choi, Effects of a magnetic field on the copper metallization using the electroplating process, Microelectron. Eng., 2008, 85, no. 2, 308-314. doi: 10.1016/j.mee.2007.06.018

27. C. O'Reilly, G. Hinds and J.M.D. Coey, Effect of a Magnetic Field on Electrodeposition: Chronoamperometry of $\mathrm{Ag}, \mathrm{Cu}, \mathrm{Zn}$, and Bi, J. Electrochem. Soc., 2001, 148, no. 10. doi: $\underline{10.1149 / 1.1402121}$

28. Y. Lin, J. Pan, H.F. Zhou, H.J. Gao and Y. Li, Mechanical properties and optimal grain size distribution profile of gradient grained nickel, Acta Mater., 2018, 153, 279-289. doi: 10.1016/j.actamat.2018.04.065

29. A. Jmiai, B. El Ibrahimi, A. Tara, S. El Issami, O. Jbara and L. Bazzi, Alginate biopolymer as green corrosion inhibitor for copper in $1 \mathrm{M}$ hydrochloric acid: Experimental and theoretical approaches, J. Mol. Struct., 2018, 1157, 408-417. doi: 10.1016/j.molstruc.2017.12.060

30. Z.Z. Tasic, M.B.P. Mihajlovic and M.M. Antonijevic, The influence of chloride ions on the anti-corrosion ability of binary inhibitor system of 5-methyl-1H-benzotriazole and potassium sorbate in sulfuric acid solution, J. Mol. Liq., 2016, 222, 1-7. doi: 10.1016/j.molliq.2016.07.016

31. M.B. Radovanović and M.M. Antonijević, Protection of copper surface in acidic chloride solution by non-toxic thiadiazole derivative, J. Adhes. Sci. Technol., 2017, 31, no. 4, 369-387. doi: $10.1080 / 01694243.2016 .1215764$

32. B. El Bahi, M. Galai, M. Cherkaoui and H. Takenouti, Electrochemical deposition mechanism of copper-zinc-tin alloy and structural characterization, Surf. Interfaces, 2020, 19, 100466. doi: 10.1016/j.surfin.2020.100466

33. F.M.F. Rhen, D. Fernandez, G. Hinds and J.M.D. Coey, Influence of a Magnetic Field on the Electrochemical Rest Potential, J. Electrochem. Soc., 2005, 153, no. 1. doi: $\underline{10.1149 / 1.2135207}$

34. X. Yu, Z. Wang and Z. Lu, In situ investigation of atmospheric corrosion behavior of copper under thin electrolyte layer and static magnetic field, Microelectron. Reliab., 2020, 108, 113630. doi: 10.1016/j.microrel.2020.113630

35. H. Huang and X. Guo, The relationship between the inhibition performances of three benzo derivatives and their structures on the corrosion of copper in $3.5 \mathrm{wt} . \% \mathrm{NaCl}$ solution, Colloids Surf., A, 2020, 598, 124809. doi: $10.1016 /$ j.colsurfa.2020.124809

36. A. Kurumada, G. Itoh, M. Sugita, T. Sakuma and M. Seki, Change of the hardness of copper sheet by splitting process, Procedia Eng., 2014, 81, 861-866. doi: 10.1016/j.proeng.2014.10.089

37. S. Ghosh, Electroless copper deposition: A critical review, Thin Solid Films, 2019, 669, 641-658. doi: $10.1016 / j . t s f .2018 .11 .016$ 